Discussion Individual factors interfering with NIHL were age, sex, infectious-disease and nonce-BMI based on analysis. The risk was arranged in order from high to low. Age was highly related to NIHL though hearing threshold had been revised by age and sex, risk was 3.638 14.876 times of reference group. Aging-hearing-loss and NIHL are too similar in audiogram, deafness classification and symptom to distinguish. So did infectious-disease, such as mumps, measles, epidemic-cerebrospinal-meningitis, rubella, chicken-pox and zoster, et al. Nonce-BMI was mildly related to NIHL, risk was 1.090 times. No evidence approved smoking drinking and length-of-service concerned with NIHL, which differed from other researches and should dig further. Good habits are important for occupational health as well as protective measure. It is necessary for employer to do exercising, keep from infectious diseases, maintain reasonable BMI, stop smoking and limit drinking

\section{PSYCHOSOCIAL CONSEQUENCES OF DEMONETISATION IN INDIA ON TEA GARDEN WORKERS: A QUALITATIVE STUDY IN 3 DISTRICTS OF WEST BENGAL}

${ }^{1}$ Priyanka Roy*, ${ }^{2}$ Annalisa Grandi, ${ }^{3}$ Rajib Dasgupta, ${ }^{4}$ Santanu K Tripathi. ${ }^{1}$ Department of Labour, Government of West Bengal, Kolkata, India: ${ }^{2}$ University of Turin, Turin, Italy; ${ }^{3}$ Jawaharlal Nehru University, New Delhi, India; ${ }^{4}$ Calcutta School of Tropical Medicine, Kolkata, India

\subsection{6/oemed-2018-ICOHabstracts. 1467}

Introduction The existence of a parallel cash-based economy is a major economic and political issues in India. The Government of India in a bid to curb corruption had notified $\neq 500$ and $\neq 1000$ as illegal tender on 8th November, 2016, and asked citizens to deposit the demonetised notes constituting $86 \%$ of total money in circulation. Commentators have indicated several hardships of common people including delayed or non-payment of wages, job loss. The tea- industry which employed 1.1 million individuals is thought to be majorly affected. However, there is no study which has assessed the psycho social consequences of demonetisation of tea garden workers (TGW's).

Methods Focus Group discussions (FGD) have been carried out with TGW's of 3 districts- Jalpaiguri, Alipurduar, and Coochbehar. In depth interviews (IDI) have been conducted with district and labour administration (4), tea garden managers (3), TGW's (6), Tea garden doctors (3), psychosocial counsellor (2), bank manger (1), worker's union (1). Semistructured topic guide would cover- experiences of demonetisation, job satisfaction, self esteem, insecurity, absenteeism, physical discomfort, addiction. An iterative approach would be taken modifying the topic guide during the course of the study. Data would be analysed based on the general guidelines of grounded theory. Multi step data analysis includes data reduction, coding and identification of dominant themes. Ethics approval has been acquired.

Results So far interaction has identified some negative psychosocial consequences due to fear of less productivity in coming seasons, drop in prices and wages and loss of job, uncertain future and migration. However, the complete results of the study will be available by 30th August 2017.

Discussion The results of the study will provide evidence on the psycho-social consequences of TGW's in relation to the job-insecurity and economic loss, if any, due to demonetisation, may contribute in future policy formulation.
566

EVALUATION OF QUALITY OF LIFE AND ANNOYANCE IN THE CONTEXT OF LIFE MONZA PROJECT

${ }^{1} \mathrm{G}$ Arcangeli*, ${ }^{1} \mathrm{~N}$ Mucci, ${ }^{2} \mathrm{G}$ Giorgi, ${ }^{3} \mathrm{C}$ Lorini, ${ }^{3} \mathrm{G}$ Bonaccorsi. ${ }^{1}$ Department of Experimental and Clinical Medicine, University of Florence, Florence, Italy; ${ }^{2}$ Department of Human Sciences, European University of Rome, Rome, Italy; ${ }^{3}$ Department of Health Sciences, University of Florence, Florence, Italy

\subsection{6/oemed-2018-ICOHabstracts. 1468}

Introduction The LIFE MONZA (Methodologies fOr Noise low emission Zones introduction And management) project aims to assess a methodology for the management of the Noise Low Emission Zones (LEZ), that are urban areas subject to traffic restrictions. The impacts of noise pollution will be analysed in the pilot area of the Municipality of Monza, partner of the project together with the Higher Institute for Environmental Protection and Research (ISPRA), the University of Florence and a private company. A relevant objective of the project concern the analysis of the effects of the introduction of the Noise LEZ on the people's well-being conditions, through the use of proper health indicators.

Methods After an analysis of the literature, we have proposed the use of the WHOQOL-Bref questionnaire for the evaluation of quality of life (QOL), that is the only tool that has a specific environmental domain. The limit of the physical space available in the general LIFE questionnaire has led us to select five main questions to be administered. Since annoyance is set of subjective feelings, its detection is normally carried out through questionnaires, but none of them is an authoritative and validated one. Consequently, we have developed a survey instrument of four questions.

Result The administration pre-post (before and after the interventions) of the nine multiple-choice questions described above and, optionally, of the WHOQOL-Bref would provide a comparable objective score of the residents' QOL and an estimate of the potential role of the structural changes on it.

Discussion The project intend to update the state of the art about the evaluation of QOL and annoyance. There is a wide literature regarding QOL evaluation as well as related tools of investigation. The scientific production regarding annoyance is more limited but the recent increasing of publications about this issue underlines its topicality and the need for further researches.

\section{ERGONOMIC DESIGN INTERVENTION TO AMELIORATE EXPOSURE TO VIBRATION DURING USE OF HAND-HELD VIBRATING TOOL FOR STONE-POLISHING ACTIVITIES IN UNORGANISED SECTOR}

${ }^{1} \mathrm{~S}$ Nath, ${ }^{1} \mathrm{~T}$ Kalita, ${ }^{2} \mathrm{R}$ Tiwari, ${ }^{1} \mathrm{~S}$ Karmakar*. ${ }^{1}$ Department of Design, Indian Institute of Technology (IIT) Guwahati, Guwahati, India; ${ }^{2}$ Department of Mechanical Engineering, Indian Institute of Technology (IIT) Guwahati, Guwahati, India

\subsection{6/oemed-2018-ICOHabstracts. 1469}

Introduction Use of hand-held vibrating tools like drill machines, polishing machines etc. are very common in unorganised sectors where users recurrently encounter occupational vibration. Vibrational energy is transmitted from the vibrating hand-tool to human body primarily through hand-arm and affects from early fatigue to irreversible hand injuries. In the present research, design modification of a hand-held stone-polishing tool was done from ergonomics and industrial design perspective to reduce transmission of vibration and improving usability. 